\title{
Hyperthermia of Magnetic Nanoparticles: An Experimental Study of the Role of Aggregation
}

\author{
SUPPORTING INFORMATION \\ Clément Guibert, Vincent Dupuis, Véronique Peyre, and Jérôme Fresnais* \\ ${ }^{1}$ Université Pierre et Marie Curie-Paris 6, UMR 8234, PHENIX, CNRS, Paris, F-75005 France \\ *Corresponding author. Université Pierre et Marie Curie-Paris 6, UMR 8234, PHENIX, CNRS, \\ Paris, F-75005 France; Email: jerome.fresnais@upmc.fr
}




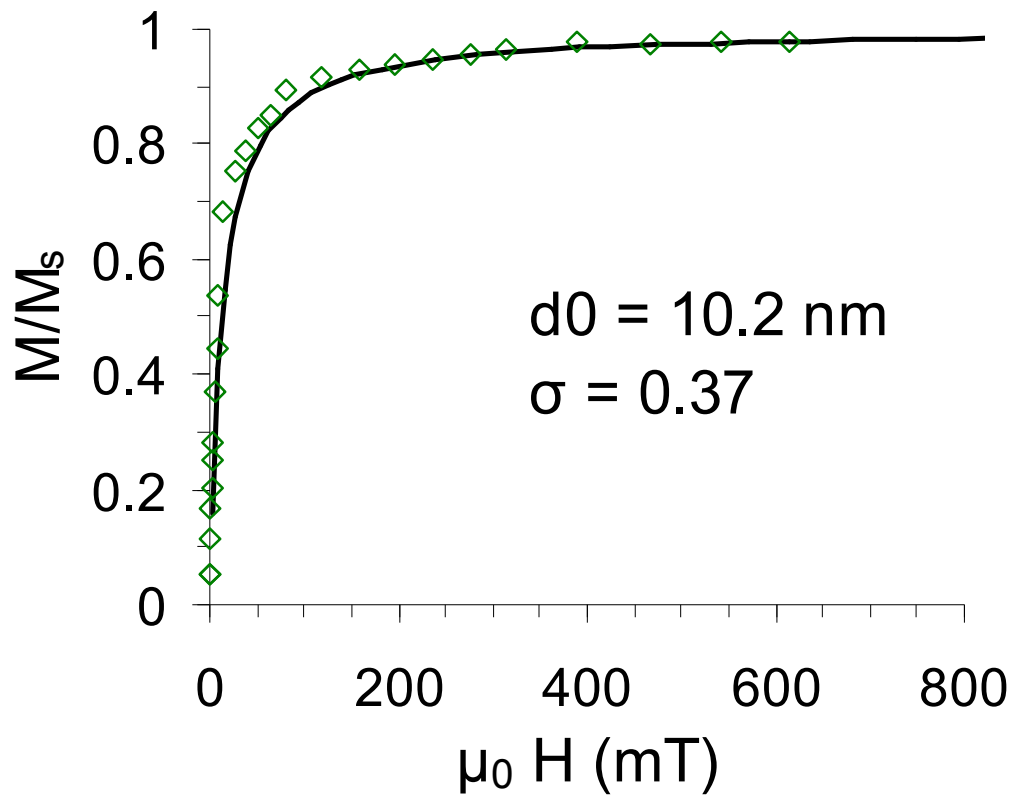

Figure SI-1. Magnetization curve for bare nanoparticles 




Figure SI-2. Dynamic light scattering correlation function for bare nanoparticles with corresponding fit at three $\mathrm{pH}$ values.

Table S1: Parameters of the Fit

\begin{tabular}{ccccccccccc}
\hline & & & $\mathrm{D}_{1}\left(\mu \mathrm{m}^{2} . \mathrm{s}^{-}\right.$ & $\mathrm{d}_{\mathrm{H} 1}$ & $\%_{\text {isolate }}$ & & $\mathrm{D}_{2}\left(\mu \mathrm{m}^{2} . \mathrm{s}^{-}\right.$ & $\mathrm{d}_{\mathrm{H} 2}$ & $\%_{\text {aggregate }}$ & $\mathrm{d}_{\text {Hmean }}$ \\
$\mathrm{pH}$ & $\mathrm{A}_{0}$ & $\mathrm{~A}_{1}$ & $\left.{ }^{1}\right)$ & $(\mathrm{nm})$ & $\mathrm{d}^{\mathrm{d}}$ & $\mathrm{A}_{2}$ & $\left.{ }^{1}\right)$ & $(\mathrm{nm})$ & ${ }_{\mathrm{d}}$ & $(\mathrm{nm})$ \\
\hline & $6.06 \mathrm{E}-$ & 0.9 & & & & 0.0 & & & & \\
2.1 & 04 & 1 & $4.41 \mathrm{E}-11$ & 22.29 & 0.94 & 6 & $1.69 \mathrm{E}-11$ & 58.04 & 0.06 & 24.33 \\
4.0 & $5.24 \mathrm{E}-$ & 0.3 & & & & 0.6 & & & & \\
8 & 04 & 5 & $4.41 \mathrm{E}-11$ & 22.29 & 0.37 & 0 & $1.71 \mathrm{E}-11$ & 77.71 & 0.63 & 57.45 \\
& $2.39 \mathrm{E}-$ & 0.2 & & & & 0.7 & & & & \\
5.2 & 03 & 1 & $1.27 \mathrm{E}-11$ & 57.42 & 0.22 & 5 & $3.41 \mathrm{E}-12$ & 288.60 & 0.78 & 238.15 \\
\hline
\end{tabular}






Figure SI-3. Form factor of bare nanoparticles obtain by SAXS 